\title{
Spatial monitoring of the courtship flight trajectory of Latham's snipe (Gallinago hardwickii) using microphone arrays
}

\author{
Shiho Matsubayashi ${ }^{1}$, Hideki Osaka ${ }^{2}$, Reiji Suzuki ${ }^{3}$, Kazuhiro Nakadai ${ }^{4}$, and Hiroshi \\ Okuno $^{5}$ \\ ${ }^{1}$ Osaka University \\ ${ }^{2}$ toriR Lab \\ ${ }^{3}$ Nagoya University \\ ${ }^{4}$ Honda Research Institute Japan Co., Ltd. \\ ${ }^{5}$ Kyoto University
}

February 10, 2022

\begin{abstract}
1. This study is the first to quantitatively measure of the courtship flights of Latham's snipe (Gallinago hardwickii), a migratory shorebird on the East Asian-Australasian Flyway, which is nearly threatened in their major breeding ground in Japan. 2. We localised the fine-scale movements of their display flights performed at high altitude and high speed, using a 16-channel microphone array, and assessed the direction from which each sound arrived using robot audition. 3. Preliminary analyses of the azimuthal and elevation angles of the display flights partially revealed a fine-scale flight trajectory, in which a male Latham's snipe gradually gained elevation while vocalising sharp and harsh repeating calls until it reached the flight peak elevation and then dove down to the ground with a winnowing along wetland zones without tall vegetation. 4 . Not only is this observation methodologically useful for better understanding Latham's snipe display flight site selection, but can also be extended to investigate other rare nocturnal or crepuscular birds, that are too timid to risk ringing or tagging.
\end{abstract}

\section{Hosted file}

matsubayashi0127. docx available at https://authorea.com/users/459890/articles/556002-spatialmonitoring-of-the-courtship-flight-trajectory-of-latham-s-snipe-gallinago-hardwickiiusing-microphone-arrays 